\title{
The Efficacy of Topical Vitamin C and Microneedling for Photoaging
}

\author{
Karina Dyahtantri Pratiwi ${ }^{1}$, Muhammad Yulianto Listiawan ${ }^{1}$, Evy Ervianty ${ }^{1}$, Cita Rosita \\ Sigit Prakoeswa ${ }^{1}$, Damayanti ${ }^{1}$, Esti Hendradi ${ }^{2}$, Sawitri $^{1}$ \\ ${ }^{I}$ Department of Dermatology and Venereology, Faculty of Medicine, Universitas Airlangga, Dr. \\ Soetomo General Academic Teaching Hospital, Surabaya, Indonesia \\ ${ }^{2}$ Medical staff of Pharmacy Faculty of Medicine Universitas Airlangga Surabaya, Indonesia
}

\begin{abstract}
Background: Photoaging is premature skin aging caused by exposure to ultraviolet (UV) radiation. Vitamin C is an antioxidant that inhibits the tyrosinase enzyme that can reduce pigmentation. Microneedling procedure can improve the penetration of topical vitamin $\mathrm{C}$, and it has skin rejuvenating effects to reduce wrinkles and minimize pore size. Purpose: The main purpose of this study was to evaluate the efficacy of topical vitamin $\mathrm{C}$ application after microneedling intervention for the clinical improvement of photoaging. Methods: Twenty-four women with photoaged skin participated in this randomization study, and they were divided into control and intervention groups. Solution of $0.9 \% \mathrm{NaCl}$ and microneedling were performed to control group, and topical vitamin $\mathrm{C}$ and microneedling were performed to intervention group. Three intervention sessions were repeated at a 2 week interval. Signs of photoaging such as pigmentation, wrinkles, and pores were evaluated using Metis DBQ3-1, and the data were obtained numerically. Result: The data analysis revealed a significant improvement in pigmentation in the intervention group compared to control group $(\mathrm{p}<0.05)$. Wrinkles and pores evaluation revealed no significant difference between the control and intervention groups. Conclusion: Topical vitamin $\mathrm{C}$ after microneedling procedure has provided a significant improvement in pigmentation compared to $\mathrm{NaCl} 0.9 \%$ after microneedling.
\end{abstract}

Keywords: photoaging, vitamin C, microneedling.

Correspondence: Sawitri, Department of Dermatology and Venereology Faculty of Medicine, Universitas Airlangga/ Dr. Soetomo General Academic Hospital, Surabaya, Jl. Mayjen Prof. Dr. Moestopo No 6-8, Surabaya, 60286, Indonesia. Phone: (031) 5501078, email: sawitri.rh@gmail.com.

\section{BACKGROUND}

As well as any other body organ, the skin can experience aging. Skin aging involves two different processes - the intrinsic and extrinsic aging process. Those processes overlap each other in clinical manifestations on the individual skin. The intrinsic aging process is known as chronological aging, which is affected by individual age, genetic factors, biochemical changes, and changes in the immune system changes. The extrinsic aging process is affected by the environment in the form of ultraviolet (UV) radiation and pollution. Extrinsic aging is mainly caused by the long-term effects of repeated exposure to UV radiation, hence photoaging develops. ${ }^{1}$

Living around the equator is a risk factor for photoaging as its daily average UV index is 10 out of 12. The severity of photoaging directly relates to the amount of UV exposure in a certain period. More than $80 \%$ signs of skin aging in individuals below 60 years are caused by chronic UV radiation associated with inflammation and connective tissue damage due to the formation of free radicals or reactive oxygen species (ROS). ${ }^{1}$
Vitamin $\mathrm{C}$ is one of the potent antioxidants in the skin. In 2005, in vitro research by Baumann showed the antioxidant effect of vitamin $\mathrm{C}$ at $18 \%$ and vitamin $\mathrm{E}$ at $10 \%$. In 2003, Lin et al. reported that a concentration of vitamin $\mathrm{C}$ improved photoaged pig skin by $70 \%$. Vitamin $\mathrm{C}$ is also known as a depigmentation agent that works by inhibiting the tyrosinase enzyme and reducing Dihydroxyphenylalanine (DOPA)-quinone, thereby reducing the formation of melanin. ${ }^{2,3,4}$

Microneedle array is a device with micron-sized needle shafts that serve as a medium to deliver topical substance. Dermapen ${ }^{\circledR}$ microneedle array is a tool that can facilitate the penetration of topical substance with short downtime. The application of microneedling will cause micro-sized skin sores on the epidermis layer to the dermis layer. The microsized skin sores would then facilitate the penetration of topical substances. 5,6

This was a study of $3 \%$ sodium ascorbyl phosphate with priorly microneedling procedure as a photoaging intervention to overcome wrinkles and facilitate drug delivery. This study was expected to contribute an overview of topical vitamin C 
administration and microneedling on the clinical improvement of photoaging.

\section{METHODS}

This experimental analytic study used randomized controlled trials to determine the clinical improvement of photoaging after topical administration of vitamin $\mathrm{C}$ with microneedling procedure priorly. Also, to compare the clinical improvements of photoaged skins between topical administration of vitamin $\mathrm{C}$ and microneedling intervention and administration of $0.9 \%$ $\mathrm{NaCl}$ and microneedling (control). Twenty-four women with photoaged skins were assigned randomly into control group and intervention group. The control group received $0.9 \% \mathrm{NaCl}$ and microneedling, and the intervention group received topical vitamin $\mathrm{C}$ and microneedling. Each group received 3 intervention sessions at a 2-week interval. The evaluation of pigmentation spots, wrinkles, and pores was carried out using the Metis DBQ3-1 (Metis) facial analysis, and the data were obtained numerically. Based on the manual, the range of values for each criterion is $1-100$. A value of 1 indicates a severe photoaging problem, and a value of 100 indicates no photoaging issue. The data were processed and tested using the SPSS 17 for Mac. This research has been examined by the Ethics Committee at Dr. Soetomo General Hospital, Surabaya.

\section{RESULT}

All subjects were female (100\%) aged 40 to 59 years. There were 7 subjects $(29.2 \%)$ in the $40-44$ years age group, 6 subjects $(25 \%)$ in the $45-49$ years age group, 6 subjects $(25 \%)$ in the $50-54$ years age group, and 5 subjects $(20.8 \%)$ in the $55-59$ years age group. The mean age of the control group was $48.5 \pm 5.6$ years, and the mean age of the intervention group was $47.6 \pm 6.2$ years.

Table 1. Basic characteristics of photoaging patients

\begin{tabular}{|c|c|c|c|c|}
\hline \multicolumn{2}{|c|}{ Variable } & \multirow{2}{*}{$\begin{array}{c}\text { Control } \\
\text { n }(\%) \\
0(0)\end{array}$} & \multirow{2}{*}{$\begin{array}{c}\text { Intervention } \\
\mathrm{n}(\%) \\
0(0)\end{array}$} & \multirow{2}{*}{$\begin{array}{c}\text { Number } \\
\mathrm{n}(\%) \\
0(0)\end{array}$} \\
\hline Sex & Male & & & \\
\hline & Female & $12(50)$ & $12(50)$ & $24(100)$ \\
\hline \multirow[t]{4}{*}{ Age } & $40-44$ years & $3(42.9)$ & $4(57.1)$ & $7(29.2)$ \\
\hline & $45-49$ years & $3(50)$ & $3(50)$ & $6(25)$ \\
\hline & $50-54$ years & $4(66.7)$ & $2(33.3)$ & $6(25)$ \\
\hline & 55-59 years & $2(40)$ & $3(60)$ & $5(20.8)$ \\
\hline \multirow[t]{2}{*}{ Glogau } & II & $6(50)$ & $7(53.8)$ & $13(54.2)$ \\
\hline & III & $6(50)$ & $5(45.5)$ & $11(45.8)$ \\
\hline Fitzpatrick's & IV & $6(50)$ & $6(50)$ & $12(50)$ \\
\hline Skin Type & $\mathrm{V}$ & $6(50)$ & $6(50)$ & $12(50)$ \\
\hline \multirow{2}{*}{$\begin{array}{l}\text { History of } \\
\text { sunscreen } \\
\text { usage }\end{array}$} & Yes & $10(83.3)$ & $9(75)$ & $19(79.2)$ \\
\hline & No & $2(16.7)$ & $3(25)$ & $5(20.8)$ \\
\hline \multirow{2}{*}{$\begin{array}{l}\text { Hitory of } \\
\text { sunscreen re- } \\
\text { application }\end{array}$} & Yes & $0(0)$ & $0(0)$ & $0(0)$ \\
\hline & No & $12(50)$ & $12(50)$ & $24(100)$ \\
\hline \multirow{2}{*}{$\begin{array}{l}\text { Duration of } \\
\text { sun exposure }\end{array}$} & 30 minutes & $4(33.3)$ & $5(41.7)$ & $9(37.5)$ \\
\hline & 60 minutes & $8(66.7)$ & $7(58.3)$ & $15(62.5)$ \\
\hline \multirow[t]{2}{*}{ Occupation } & Indoor & $12(50)$ & $12(50)$ & $24(100)$ \\
\hline & Outdoor & $0(0)$ & $0(0)$ & $0(0)$ \\
\hline Total & & $12(50)$ & $12(50)$ & $24(100)$ \\
\hline
\end{tabular}

Table 2. The comparison of the evaluation results of pigmentation spots in control and intervention groups

\begin{tabular}{lccc} 
& $\begin{array}{c}\text { Control Group } \\
(\mathrm{n}=12)\end{array}$ & $\begin{array}{c}\text { Intervention Group } \\
(\mathrm{n}=12)\end{array}$ & $\mathrm{p}$-value \\
\hline Metis I & Average $\pm \mathrm{SD}$ & Average \pm SD & $0.58^{*}$ \\
Metis II & $63.17 \pm 6.408$ & $62.25 \pm 11.307$ & $0.21^{* *}$ \\
Metis III & $66.08 \pm 6.9$ & $61.33 \pm 11.11$ & $0.03 * *$ \\
\hline
\end{tabular}

*Mann-Whitney Test; **Unpaired t-test

$\mathrm{SD}=$ standard deviation 
The result evaluation of pigmentation spots showed a mean decrease in Metis group II. In contrast, in Metis group III, the mean of pigmentation spots increased. The test results were statistically significant, with $\mathrm{p}<0.05$. Further tests with the pairwise comparison between Metis I and Metis III $(p=0.023)$ and Metis II and Metis III $(\mathrm{p}=0.0)$ showed significant results. In contrast, the Metis I and Metis II tests results were not statistically significant $(p=0.30)$.

The evaluation of Metis I and II pigmentation spots used an appropriate statistical test based on the results of the data normality test. The statistical tests showed that there were no significant differences in pigmentation spots between the control group and the intervention group (Table 2).

Metis III pigmentation spots was analyzed using unpaired t-test. The statistical tests showed an increase in the mean of intervention group $(66.25 \pm$ 6.31). There was a significant difference in pigmentation spots between control group and intervention group (Table 2).

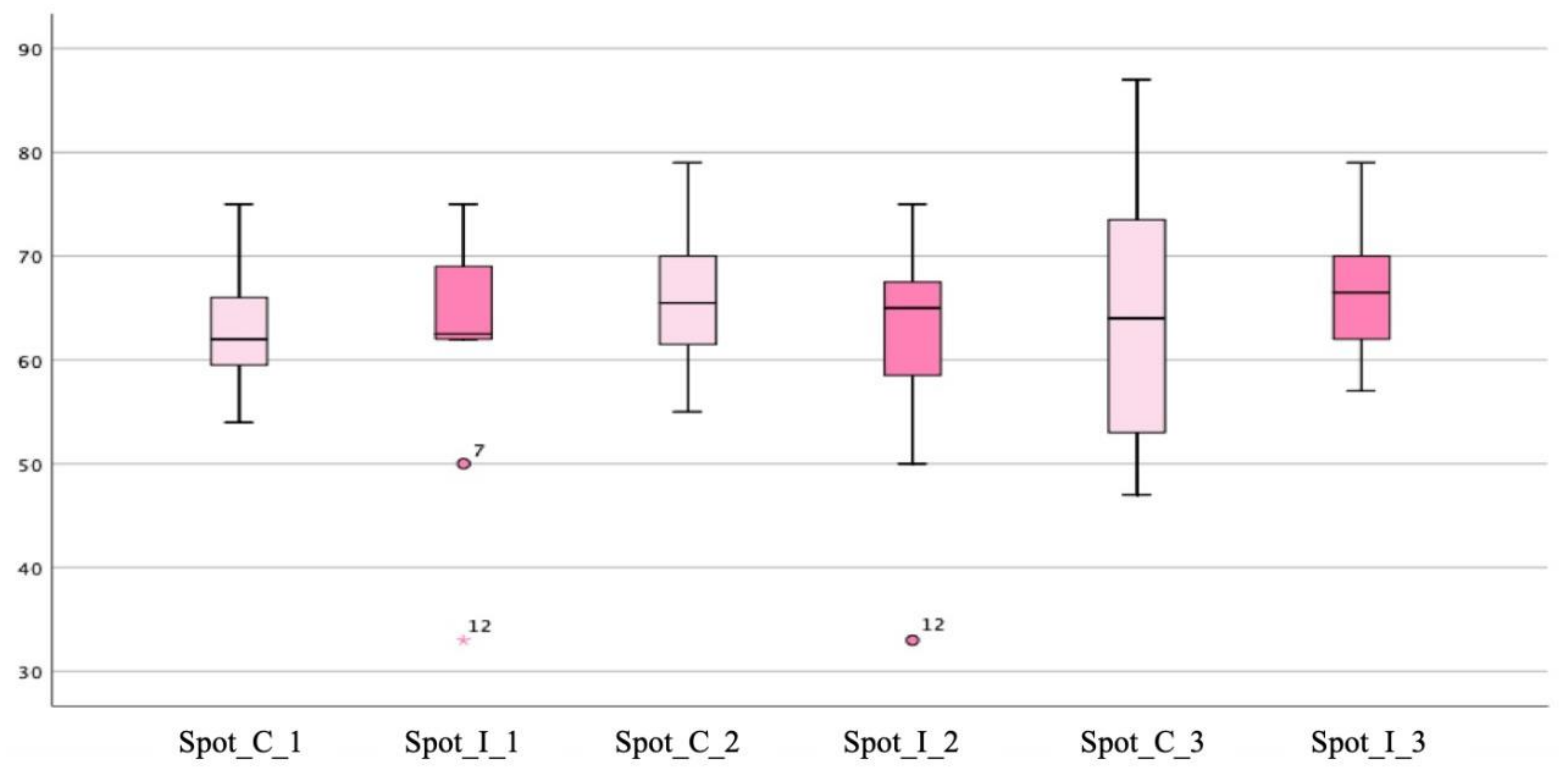

Figure 1. Boxplots of pigmentation spots in control group and intervention group.

The evaluation results of wrinkles showed an increase in mean score in Metis II and III, 56.41 \pm 11.07 , and $58.17 \pm 7.44$, respectively. The difference was statistically significant with $\mathrm{p}=0.03$. The pairwise comparison test between Metis I and Metis II showed the value of $\mathrm{p}=1.00, \mathrm{p}=0.48$ between Metis I and Metis III, and $\mathrm{p}=0.84$ between Metis II and Metis III. Those results were not statistically significant.

The average of wrinkles on intervention group research was initially 55.58 , increased to 56.41 in the second evaluation, and finally increased again to 58.16. The statistical tests were performed to compare wrinkles between the control group and intervention group. We used unpaired t-test in Metis I, II, and III wrinkle analysis as the control and intervention group data, each showed normal distribution. The unpaired ttest results of the evaluation of Metis I, II, and III in wrinkles between the control and intervention groups were $\mathrm{p}=0.57, \mathrm{p}=0.32$, and $\mathrm{p}=0.24$, respectively, and they were not statistically significant.

Table 3. The comparison of the evaluation results of wrinkles in the control group and intervention group

$$
\text { Control Group Intervention Group }
$$

$(n=12)$

$$
(\mathrm{n}=12)
$$

\begin{tabular}{lccc}
\hline & Average \pm SD & Average \pm SD & p-value* \\
\hline Metis I & $54.33 \pm 9.85$ & $55.58 \pm 13.31$ & 0.57 \\
Metis II & $53 \pm 5.18$ & $56.41 \pm 11.07$ & 0.32 \\
Metis III & $57.92 \pm 12.38$ & $58.17 \pm 7.44$ & 0.24 \\
\hline
\end{tabular}

*Paired t-test

$\mathrm{SD}=$ Standard deviation 


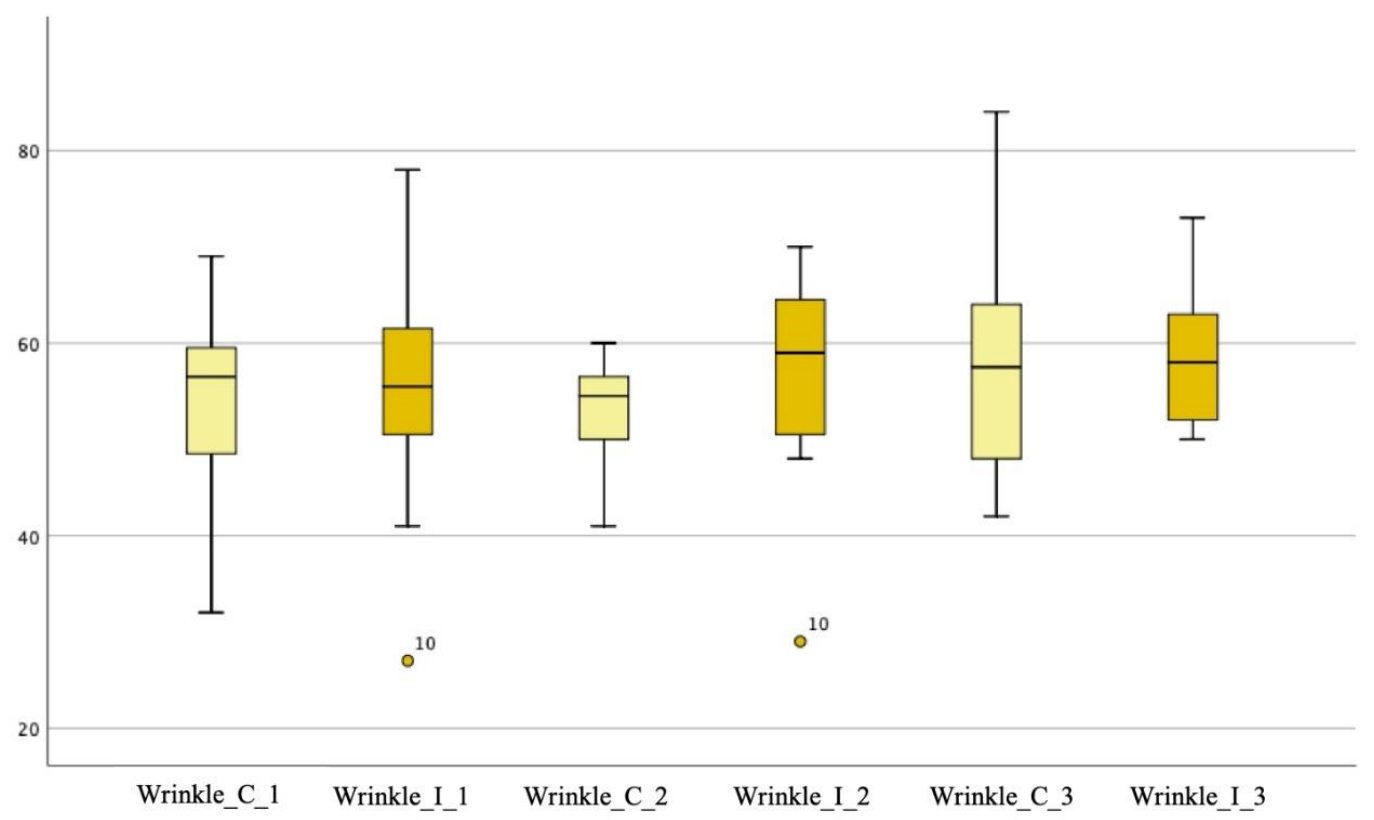

Figure 2. Boxplots of wrinkle at control and intervention group.

Table 4. The comparison of the evaluation results of pores in the control group and intervention group

\begin{tabular}{|c|c|c|c|}
\hline & $\begin{array}{l}\text { Control } \\
(\mathrm{n}=12)\end{array}$ & $\begin{array}{l}\text { Intervention } \\
\quad(\mathrm{n}=12)\end{array}$ & \\
\hline & Average \pm SD & Average \pm SD & p-value \\
\hline Metis I & $92.25 \pm 2.37$ & $91.33 \pm 2.42$ & $0.96^{*}$ \\
\hline Metis II & $92.91 \pm 3.208$ & $91.66 \pm 5.1$ & $0.36 * *$ \\
\hline Metis III & $92.5 \pm 4.23$ & $91 \pm 10.9$ & $0.19 * *$ \\
\hline
\end{tabular}

*Unpaired t-test; **Mann-Whitney Test

$\mathrm{SD}=$ Standard deviation

The Shapiro-Wilk test for pores evaluation result showed that the Metis III data were not normally distributed with a p-value $<0.05$. The Friedmann test results showed an average increase in Metis III evaluation, with $\mathrm{p}=0.025$, meaning that there were statistically significant differences. Further tests for pores analysis between intervention groups with pairwise comparison showed no significant results. Metis I and Metis II showed a value of $p=0.25$, Metis I and Metis III showed a value of $\mathrm{p}=0.83$, and the Metis II and Metis III showed a value of $\mathrm{p}=0.59$.

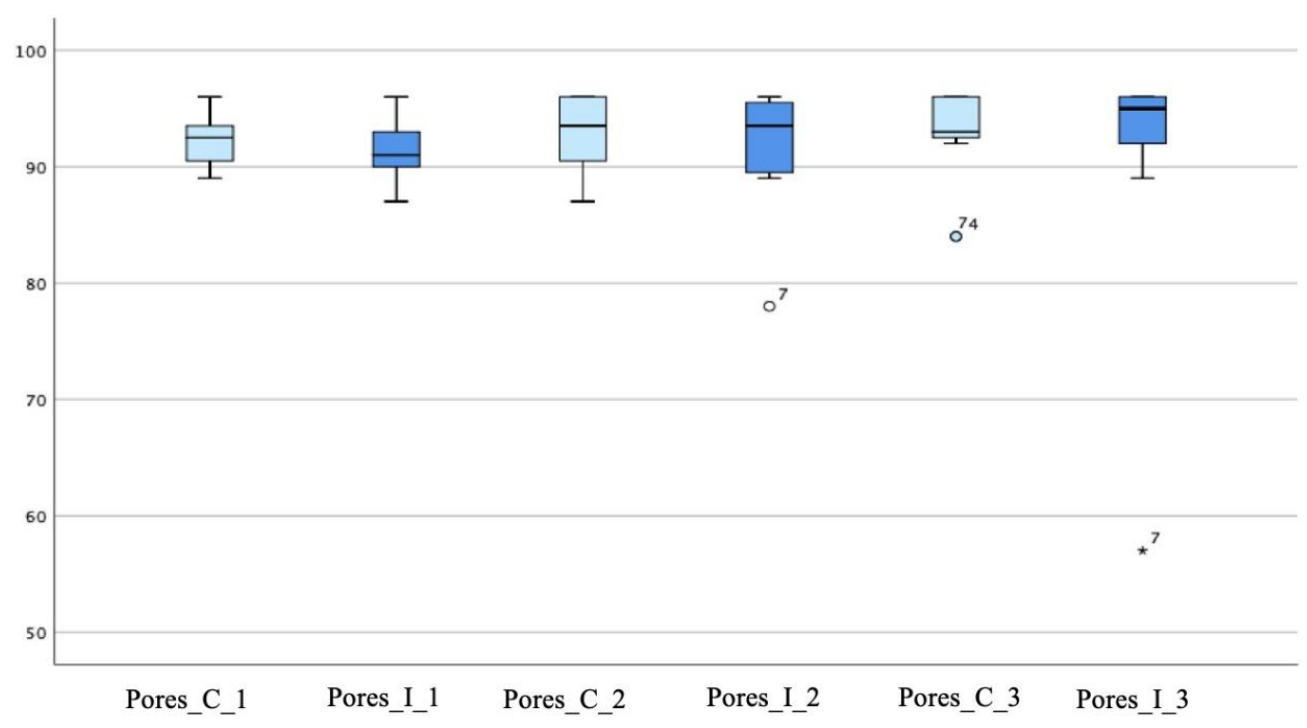

Figure 3. Boxplots of pores at the control and intervention group. 


\section{DISCUSSION}

All subjects were female who experienced photoaging. This was because there are physiological differences in the skin structure between male and female. Male have a thicker epidermal layer than female, and the dermis layer of male contains more collagen than that on female. Furthermore, male produce more sebum in relation to testosterone hormone, affecting the enlargement of pore size. All subjects were in the 40-59 years age group, one of the photoaging criteria based on Glogau II-III. The Glogau II age group category is $40-49$ years, while the Glogau III category is $50-59$ years. The mean age of the intervention group subjects was $47.6 \pm 6.2$ years. The youngest subject was 40 years old, and the oldest was 58 years old. This is consistent with the 2018 photoaging research by Pratiwi et al. conducted in Surabaya, Indonesia. They compared stem cell administration and microneedling. ${ }^{7,8}$

There were 13 subjects $(54.2 \%)$ in the Glogau II category, and 11 subjects $(45.8 \%)$ were in the Glogau III category. This is in line with a 2018 study by ElDomyati et al. on skin rejuvenation for photoaged skin. They examined combinations of microneedling with minimally invasive procedures such as plateletrich plasma or chemical peeling with trichloroacetic acid $15 \%$. Photoaging patients in Glogau II-III category tend to report a complaint of photoaging problems, while patients in Glogau I category do not. Furthermore, patients in Glogau I category might cover the photoaging signs with cosmetics. Photoaging patients in the Glogau IV category have more visible clinical signs of chronological aging than those in Glogau I-III that it become a confounding factor. Chien et al. in 2015 stated that wrinkles due to chronological aging do not appear until around the age of 50 in Fitzpatrick's IV-VI skin type populations. The diagnosis of photoaging in Fitzpatrick's IV-VI skin type can be made subjectively if clinical signs of photoaging such as pigmentation spots, wrinkles, and enlarged pores are present. ${ }^{9,10}$

Avoiding UV radiation in equator including Indonesia is difficult. Indonesia is located around the equator at $6^{\circ}$ north latitude and $11^{\circ}$ south latitude, which affects the reception of UV radiation exposure. Twenty-four subjects worked in Surabaya. All subjects were domiciled in Surabaya or surrounding areas with a duration of daily direct exposure to UV radiation ranging from 30 to 60 minutes during the daily commute. Forty one point seven percent of the subjects in the intervention group were exposed to direct UV radiation for 30 minutes per day, and $58.3 \%$ of the subjects in the intervention group were exposed to direct UV radiation for 60 minutes per day.

The initial skin evaluation observation (week 0) showed that all subjects had pigmentation spots, which is a sign of photoaging. Initially, the mean of pigmentation spots in the control group was 63.16 , and the mean of pigmentation spots in the intervention group was 62.25.

Pigmentation spots occur as UV radiation directly affects melanocytes - the cells in the epidermal layer that responsible for melanin production. Long-term sun exposure increases the density of melanocytes twofold than protected skin. Interleukin (IL)-1, IL-6, IL-8, Transforming Growth Factor (TGF- $\beta$ ), and C1 leukotriene formed during UV exposure, increasing the melanin production in melanocytes. These cytokines, growth factors, and inflammatory mediators directly stimulate the growth and proliferation of melanocytes. Research by Taylor in 2005 is in line with the preceding research by Gilchrest's research in 1996 on the role of UV radiation in triggering pigmentation spots. ${ }^{11}$

Ultraviolet radiation can increase the activity of the tyrosinase enzyme that it will change more tyrosine to DOPA-quinone. This causes melanocytes to produce more melanin pigments. Melanin synthesis occurs in melanocytes from the basal layer of the epidermis, and it can be transferred to keratinocytes so that melanin is distributed to the epidermis. The melanin accumulation manifests clinically as a pigmentation spot. ${ }^{12}$

Changes in pigmentation as a clinical sign of photoaging play an important role because pigmentation spots are the earliest photoaging signs seen on Asian racial skin, as revealed by preliminary research by Goh in 1999 involving 1500 participants in the Asian population in Singapore. Furthermore, a study by Tobin in 2017 involving 407 research subjects identified that pigmentation spots were the main characteristics in Asian populations. ${ }^{13}$

All subjects in this study belong to the Asian population with Fitzpatrick's IV-V skin type. Pigmentation spots as a dominant sign of photoaging in Asian populations are very likely related to the statement of Knaggs in 2009 that most Asian populations have relatively dark-colored skin that is Fitzpatrick's IV skin type and above. It is known that darker skin color has a greater amount of proteaseactivated receptor-2 (PAR-2). PAR-2 is a receptor involved in the melanosome transfer from melanocyte cells to keratinocytes. The amount of PAR-2 in keratinocytes can increase when triggered by ultraviolet radiation. This explains the pile of pigment in skin exposed to ultraviolet radiation. ${ }^{14}$ 
The mean of pigmentation spots of the intervention group was 62.25 at the beginning, decreased to 61.3 in the second evaluation, and increased 66.25 at the end of the study. The pigmentation spots decreased in the mid-observation (week 4) in the intervention group. This could be influenced by various factors, including outdoor activities on weekends, proper sunscreen application during the study, and proper sunscreen reapplication every two hours.

The comparison of pigmentation spots between the control and intervention group showed no statistically significant value in Metis I $(p=0.58)$ and II $(p=0.21)$ but showed a statistically significant value in Metis III with $p<0.05$. In 2009, Shimada et al. reported that vitamin $\mathrm{C}$ inhibits melanogenesis by reducing oquinones production. In 2006, Sakamoto et al., as quoted by Baumann in 2005, found that vitamin C derivatives in phosphate form were able to suppress melanin formation by up to $80 \%$. In 2017 , Effendy et al. conducted a study on the efficacy of stem cells and vitamin $\mathrm{C}$ derivatives in the form of sodium ascorbyl phosphate 3\% for photoaging intervention in Surabaya. The research reported a significant improvement of dark spots in the group receiving Metabolic Product-Amniotic Membrane Stem CellVitamin C (MP-AMSC-VC) and microneedling on week $8 .^{3,12,15}$

The administration of topical vitamin $\mathrm{C}$ derivatives in the form of $3 \%$ sodium ascorbyl phosphate as a depigmentation agent in the intervention group was thought to inhibit the tyrosinase enzyme activity to reduce the formation of quinone DOPA; therefore, reducing the formation of melanin. Topical vitamin $\mathrm{C}$ as an antioxidant can counteract the effects of ultraviolet exposure responsible for free radicals formation that triggers cytokines, growth factors, and inflammatory mediators, stimulating the growth and proliferation of melanocytes, thereby reducing melanogenesis. Furthermore, proper sunscreen reapplication and a hat or umbrella can also affect pigmentation spot formation.

All subjects had complained about wrinkles. The objective assessment of wrinkles was carried out using the Metis DBQ3-1 evaluation. The initial mean of wrinkles (week 0) in the control group was 54.3, and 55.58 in the intervention group.

Sun exposure promotes the formation of wrinkles through reduced stress strength, elasticity, and it can cause degradation of structural components that support the dermal extracellular matrix. Ultraviolet radiation can increase ROS and trigger protein activator -1 (AP-1), which increases the production of matrix metalloproteinase (MMP), thus causing collagen damage. Reactive oxygen species also induces nuclear factor kappa B (NFkB) transcription, which produce a number of mediators that contribute to skin inflammation. The process will simultaneously cause a decrease in collagen production and an increase in collagen damage, giving rise to clinical manifestations in the form of wrinkles. ${ }^{16}$

Fitzpatrick and Rostan, in 2003, as cited in Farris's study in 2006, examined the administration of topical vitamin $\mathrm{C}$ in the form of L-ascorbic acid 10\% and tetrahexydecyl ascorbate $7 \%$ in polysilicon gel bases on photoaged skins. ${ }^{23}$ The observations took 12 weeks, and clinical improvement scores obtained wrinkles significantly and the addition of collagen fiber density from histopathological results. ${ }^{17}$

We used vitamin $\mathrm{C}$ derivatives of $3 \%$ sodium ascorbyl phosphate in the form of serum. In 2017 , Effendy et al. conducted a study on the efficacy of stem cells and vitamin $\mathrm{C}$ derivatives in the form of $3 \%$ sodium ascorbyl phosphate for photoaging intervention. The study reported a significant improvement of wrinkles in the group receiving MPAMSC-VC and microneedling and meaningless result in the group treated with MP-AMSC and microneedling. ${ }^{15}$

We found significant differences in the value of wrinkles in each control group and intervention group with $\mathrm{p}<0.05$. The mean of wrinkles in week 0 of the control group was 54.3 and 57.91 in week 8 . The mean of wrinkles in the week 0 intervention group was 55.58 and 58.16 in week 8 .

The Dermapen ${ }^{\circledR} \quad$ contained $36 \quad 0.5-\mathrm{mm}$ needles, and it was rolled onto the skin to make numerous punctures into the stratum corneum to the papillary dermis. The papillary dermis contains bundles of collagen fibers intertwined with elastin fibers, namely elaunin and oxytalan fibers. The collagen and elastin together form a connected network that runs in a parallel orientation. The microneedling action with $0.5-\mathrm{mm}$ needles provides a mild injury stimulus character that can reach up to the papillary dermis and stimulates the formation of collagen and elastin, so as to improve wrinkles. ${ }^{16}$

The results of the comparison of wrinkles between the control and intervention groups showed no significant difference. This was possible because of nonoptimal Vitamin $\mathrm{C}$ concentration and different durations to reach the collagen remodelling peak. In 2012, Liebl and Cloth stated that, histopathologically, the addition of quantitative collagen begins to appear in 2-8 weeks after the intervention. The average peak in collagen maturation is reached in 6 weeks. ${ }^{20}$ In this study, the skins were evaluated two weeks after the 
intervention, so it was possible that the collagen maturation peak has not been reached.

Enlarged pore is one of the clinical signs of photoaging. Pores are superficial skin structures; therefore, changes in the shape of pores will be easily visible if the underlying structure is damaged. The initial mean of pores was 92.25 in the control group and 91.33 in the intervention group.

Enlarged pores are affected by damage to the elastin fibers and collagen fiber. The second triggering factor for damage to the dermis component is free radicals promoted by UV radiation. UV-induced ROS activates the kinase signalling in corneocyte cells of the epidermis and fibroblasts. Activator protein (AP)-1 is activated via the mitogen-activated protein kinase (MAPK) signaling pathway and the control matrix metalloproteinase (MMP) transcription. UV-induced damage to collagen fibers and elastin fibers causes the braiding of both to form fragments that accumulates in the dermis, thereby reducing the integrity of the skin structure. ${ }^{19}$

The pathogenesis of enlarged pores is thought to be due to the skin losing its ability to stretch and return to its original form, which specifically affects the integrity of the elastin fibers. Decreased skin elasticity causes skin pores to enlarge. Microfibril-associated glycoprotein-1 (MAGP-1) is an extracellular matrix protein that is important for the formation of elastin fibers. MAGP-1 plays an important role in the preparation of elastin fibers by combining elastin, collagen, fibrils, and proteoglycans. They become complex dermal structures that regulate the elasticity of pores and follicles. In 2013, Zhang et al. on dermal fibroblast culture observed the formation of MAGP-1, which was very smooth and shorter than fibrillin-1. Microfibril-associated glycoprotein-1 in the culture was exposed three times with UV A radiation $50 \mathrm{~mJ} / \mathrm{cm}^{2}$ at a 24-hour interval per dose. The study found a significant reduction in MAGP-1. The extracellular matrix protein appeared to lose the regularity of the pattern, which is to be mutually separate and irregular. Thus, it can be concluded that UV radiation inhibits the formation or accelerates the degradation of the MAGP-1 web in the elastin fibers. Photoaging decreases MAGP-1 in the follicular region of the pore, resulting in fragility and instability of the extracellular matrix, which contributes to the appearance of enlarged pores. ${ }^{20}$

In 2017, Effendy et al. reported a faster improvement in the group treated MP-AMSC-VC and microneedling than the group treated with MPAMSC and microneedling. ${ }^{15}$

In week 8 , we found no significant difference in pore values in the control group and significant differences in pore values in the intervention group with $p<0.05$. The comparison of pores between the control group and the intervention group showed no significant difference. This was possible as both groups received microneedling intervention with $0.5-\mathrm{mm}$ needles that can reach the elastin fibers at the papillary dermis level. Microfibril-associated glycoprotein-1 is a microfibril supporting the structure of pores and is closely related to elastin fibers. Injury to the papillary dermis due to a micro-sized needle can trigger the remodeling of elastin fibers, thereby forming a more compact dermis structure and triggering the formation of MAGP-1. This manifests clinically in the form of smaller pores. ${ }^{19.20}$

There was no significant difference between the two groups, and it was possible because of non-optimal vitamin $\mathrm{C}$ concentrations and early observation. The observation took place on week 8 , which was 2 weeks after the third intervention. It was thought that the remodelling of complex dermal structures, including elastin fibers, had not peaked.

Possible side effects in this study include persistent erythematous macules, hypopigmented macules, post-inflammatory hyperpigmentation, pain, and infections. In this study, no side effect was reported. This was possible because microneedling is a minimally invasive measure, and the injuries caused are thought to be resolved immediately with topical vitamin $\mathrm{C}$ as an anti-inflammatory agent.

The administration of topical vitamin $\mathrm{C}$ and the microneedling action for photoaging intervention have provided significant differences in pigmentation spots, wrinkles, and pores. The provision of topical vitamin $\mathrm{C}$ and microneedling as photoaging therapy is a potential in the field of dermatology. The limitation of the study was the inability to monitor the subjects for sun exposure during weekend activities and the proper use of sunscreen. Additionally, serum vitamin $\mathrm{C}$, which is $3 \%$ sodium ascorbyl phosphate, is relatively easy to oxidize that new preparation was needed every period. Further research with an extended observation on topical application of vitamin $\mathrm{C}$ and microneedling is needed to determine the long-term and side effects.

\section{REFERENCES}

1. Helfrich YR, Sachs DL, Voorhees JJ. Overview of skin aging and photoaging. Dermatol Nurs 2008; 20(3): p. 177-83.

2. Masaki, H. Role of antioxidants in the skin: Antiaging effects. J Derm Sci 2008; 1: p. 85-90.

3. Baumann. Sodium Ascorbyl Phosphate. 2005. Accessed 2019 October 21 from http://www.drbaumann-international.co.uk/science/BASF $\% 20$ Vitamin \%20C.pdf 
4. Lin JY, Selim MA, Shea CR, Grichnik JM, Omar MM, Monteiro-Riviere NA, Pinnell SR. UV photoprotection by combination topical antioxidants vitamin $\mathrm{C}$ and vitamin E. J Am Acad Dermatol 2003; 48(6): p. 866-74.

5. Nair PA, Arora TH. Microneedling using dermaroller a means of collagen induction therapy. Gujarat Medical Journal 2014; 69: p. 247.

6. Loesch MM, Somani AK, Kingsley MM, Travers JB, Spandau F. Skin resurfacing procedures: new and emerging options. Clin Cosm Invest Dermatol 2014; 7: p. 231-41.

7. Makino ET, Jiang LI, Priscilla Tan BA, Cheng, Tsing, Mehta, Rahul. Áddressing male facial skin concerns: clinical efficacy of a topical skincare treatment product for men. J Drugs Dermatol 2018; 17(3): p. 301-6.

8. Pratiwi, Murtiastutik, Prakoeswa. Efek pemberian topikal produk metabolit amniotic membrane stem cell (PM-AMSC) pada penuaan kulit. Berkala Ilmu Kesehatan Kulit dan Kelamin 2018; 30(2): p. 96-101.

9. El-Domyati M, Attia S, Saleh F, Brown D. Intrinsic aging vs photoaging: a comparative histopathological, immunohistochemical, and ultrastructural study of skin. Exp Dermatol 2018; 11: p. 398-405.

10. Chien AL, Qi J, Grandhi R. Photoaging in african-american skin: a reliable photonumeric scale reveals age, male gender, and sun exposure as contributory factors. J Invest Dermatol 2015; 135: p. 28.

11. Taylor SC. Photoaging and pigmentary changes of the skin. In: Buergess (ed.). Cosmetic Dermatology. Berlin: Springer 2005; p. 29-49.

12. Shimada. Effects of Ascorbic Acid on Gingival Melanin Pigmentation. J Periodontol 2009; 80(2): p. 317-23

13. Tobin DJ. Introduction to skin aging. $\mathrm{J}$ Tissue Viability 2017; 26(1): p. 37-46.

14. Knaggs H. Skin aging in the Asian population. In: Dayan, N (ed.). Skin Aging Handbook. New York: William Andrew Publishing. 2009: p. 177201.

15. Effendy ZF. Efikasi pemberian topikal campuran produk metabolic amniotic membrane stem cell (AMSC) dan vitamin $\mathrm{C}$ setelah microneedling pada photoaging. Surabaya: Universitas Airlangga. 2017: p. 25-37.

16. Vasconcelos EM, Takano D. Microneedling: experimental study and classification of the resulting injury. Surg Cosmet Dermatol 2013; 5(2): p. 1104.

17. Farris. Topical vitamin C: a useful agent for treating photoaging and other dermatologic conditions. Dermatol Surg 2006; 31: p. 814-818.

18. Liebl H, Kloth LC. Skin cell proliferation stimulated by microneedles. J Amer College Clin Wound Specialists 2012; 4(1), p. 2-6.

19. Ichihashi M, Ando H, Yoshida M, Niki Y, Matsui M. Photoaging of the skin. Anti-Aging Medicine 2009; 6(6): p. 46-59.

20. Zheng Q, Chen S, Chen Y, Lyga J, Wyborksi R, Santhanam U. Investigation of age-related decline of microfibril-associated glycoprotein-1 in human skin through immunohistochemistry study. Clin Cosmet Investig Dermatol 2013; 3: p. 317-25. 